\title{
Prevalência da recusa familiar quanto a doação de órgãos para transplante no estado de Rondônia
}

\author{
Prevalence of family refusal regarding the donation of organs for transplantation in the \\ state of Rondônia
}
Prevalencia del rechazo familiar en cuanto a la donación de órganos para trasplante en el estado de Rondônia

Fabíola de Oliveira Alcântara ${ }^{1}$, Vanúbia Calixto Oliveira ${ }^{1 *}$, Ivana Annelly Cortez da Fonseca ${ }^{1}$, Fabiana de Araújo Silva'.

\section{RESUMO}

Objetivo: Conhecer a prevalência da recusa familiar para a doação de órgãos para transplante em Rondônia. Métodos: Trata-se de um estudo exploratório-descritivo com abordagem quantitativa e documental retrospectiva. A coleta de dados ocorreu mediante a descrição do perfil dos doadores foi delineado um roteiro de coleta, constituído de análise da faixa etária; Sexo; Causa da morte; estado civil, grau de parentesco do entrevistado, decisão da família, e motivo da decisão. Resultados: A pesquisa constituiu-se da análise de 106 registros de potenciais doadores os quais a entrevista familiar foi realizada. Para este estudo, foram utilizados apenas os registros em que houve a recusa familiar para a doação dos órgãos, totalizando 63. As causas mais frequentes foram: à crença religiosa (30\%), doador contrário em vida (22\%), discordância entre familiares (16\%), prolongamento do sofrimento (11\%), a demora em liberar o corpo (8\%), a não aceitação da manipulação do corpo (8\%). Conclusão: Os motivos de recusa incubem à carência de informação e propaganda sobre o processo de doação, sendo preciso publicações de campanhas educativas efetuadas com o propósito de clarificar a população sobre este assunto, visando reduzir os resultados negativos devido à recusa familiar.

Descritores: Doação de órgãos, Família, Recusa, Morte encefálica.

\begin{abstract}
Objective: To know the prevalence of family refusal to donate organs for transplantation in Rondônia. Methods: This is an exploratory - descriptive study with retrospective quantitative and documentary approach. The collection of data occurred through the description of the profile of the donors, a collection route was drawn up, consisting of analysis of the age group; Sex; Cause of death; marital status, relationship of the respondent, family decision, and reason for decision. Results: The study consisted of the analysis of 106 records of potential donors to whom the family interview was conducted. For this study, only the records in which there was a family refusal to donate the organs were used, totaling 63 . The most frequent causes were: religious belief $(30 \%)$, contrary life giver $(22 \%)$, family disagreement $(16 \%)$, prolonged suffering $(11 \%)$, delay in releasing the body (8\%), non-acceptance of body manipulation (8\%). Conclusion: The reasons for refusal are due to the lack of information and propaganda about the donation process, and the need for publications of educational campaigns aimed at clarifying the population on this subject, aiming to reduce negative results due to family refusal.
\end{abstract}

Descriptors: Organ donation, Family, Denial, Brain death.

1'Faculdade Interamericana de Porto Velho - UNIRON - Porto Velho/Rondônia. *E-mail: vanubi_oliveira@hotmail.com.br 


\section{RESUMEN}

Objetivo: Conocer la prevalencia del rechazo familiar para la donación de órganos para trasplante en Rondônia. Métodos: Se trata de un estudio exploratorio-descriptivo con abordaje cuantitativo y documental retrospectivo. La recolección de datos ocurrió mediante la descripción del perfil de los donantes fue delineado un guión de recolección, constituido de análisis del grupo de edad; el sexo; Causa de la muerte; estado civil, grado de parentesco del entrevistado, decisión de la familia, y motivo de la decisión. Resultados: La investigación se constituyó del análisis de 106 registros de potenciales donantes a los que se realizó la entrevista familiar. Para este estudio, sólo se utilizaron los registros en que hubo el rechazo familiar para la donación de los órganos, totalizando 63. Las causas más frecuentes fueron: a la creencia religiosa $(30 \%)$, donante contrario en vida $(22 \%)$, discordancia entre familiares $(16 \%)$, la prolongación del sufrimiento (11\%), la demora en liberar el cuerpo (8\%), la no aceptación de la manipulación del cuerpo (8\%). Conclusión: Los motivos de rechazo remiten a la falta de información y divulgación sobre el proceso de donación, siendo necesario que las campañas educativas sean realizadas con el objetivo de esclarecer a la población sobre esta temática, buscando disminuir las negativas debido al rechazo familiar.

Descriptores: Donación de órganos, Familia, Denegación, Muerte.

\section{INTRODUÇÃO}

A doação de órgãos e tecidos para transplante tem sido uma temática bastante abordada no mundo inteiro. Na população em geral é pouco entendida, por outro está envolvido em inúmeras e intensas questões, da ótica política, profissional, econômico e cultural (DALBEN GG e CAREGNATO RCA, 2014).

No Brasil, a demora por um órgão para transplante ainda é grande, pois a busca não é preenchida pela atual disponibilidade de órgãos doados para realização dos transplantes. Porém, existem experiências significativas nos avanços nessa área no país, sendo que no estado de São Paulo, mostram os maiores índices de doações efetivas com órgãos transplantados. Atualmente, o estado de Rondônia possui apenas um hospital credenciado pelo Ministério da Saúde (MS) para realização de processos de transplantes de córneas e de rins (ABTO, 2017).

A Lei Federal no 10.211, de 23 de Março de 2001, que ressalta o consentimento no processo de doação de órgãos é consentido pelo cônjuge, companheiro ou parente, maior de idade, obedecida a linha sucessória, reta ou colateral, até o segundo grau, vigorando somente o consentimento familiar para autorizar a doação de órgãos e tecidos, atualmente sendo válido por esse modelo (BRASIL, 2017).

A recusa familiar, representa um grande obstáculo para a realização dos transplantes, assim como a falha na identificação e notificação de potenciais doadores e elevado índice de contraindicações clínicas para a doação (MORAES EI e MASSAROLLO MCKB, 2013).

Entre os fatores que podem levar a não aceitação da temática da doação, pode-se citar a falta de conhecimento/informação sobre o processo de doação/transplante, o temor pelo comércio de órgãos, crenças religiosas, aspectos socioeconômicos e educacionais, questões de gênero, raça/etnia e geração, valores religiosos relacionados ao corpo no pós-morte, a desconfiança e o desconhecimento sobre o diagnóstico de Morte Encefálica (ME), que podem gerar conflitos na tomada de decisão sobre a ação de doar ou não (NUNES DD et al., 2013).

Segundo dados da Associação Brasileira de Transplante de órgãos (ABTO), as taxas de recusa das famílias brasileira entre os anos de 2015 a 2017 representa 44\% da não concretização de doação de potenciais doadores. Esses números tornam -se maiores no estado de Rondônia, que superam a média nacional de 83\% de rejeição à doação (ABTO, 2017).

O presente estudo levanta o seguinte questionamento acerca do tema abordado: Quais os principais motivos da recusa familiar durante o processo de doação de órgãos para transplante no Estado de Rondônia? A pesquisa teve por objetivo conhecer a prevalência da recusa familiar para a doação de órgãos para transplante em Rondônia. 


\section{MÉTODOS}

Trata-se de um estudo descritivo, documental retrospectivo, exploratório, de natureza quantitativa, desenvolvido na Organização de Procura de Órgãos (OPO), que está vinculado a Central de Transplantes do Estado de Rondônia (CET/RO), situada no município de Porto Velho no Estado de Rondônia, Brasil.

Os dados do estudo foram obtidos por meio da análise dos registros de termos de a recusa das famílias durante o processo de doação de órgãos no Estado de Rondônia. A coleta de dados ocorreu de 07 a 11 de janeiro de 2019, mediante formulário pré-elaborado com as seguintes variáveis: faixa etária, sexo; causa da morte; estado civil, grau de parentesco do entrevistado, decisão da família, e motivo da decisão. Os dados da pesquisa compreenderam o período de janeiro de 2015 a dezembro de 2017.

Após coleta de dados realizou-se interpretação dos dados sociodemográficos e dos relativos à motivação da recusa familiar para a doação de órgãos para transplante em Rondônia: Tendo como categorias o perfil dos potenciais doadores de órgão, as causas do óbito, como também a representação dos motivos da recusa familiar quanto a doação de órgãos. Os resultados foram analisados por intermédio em uma planilha eletrônica no programa Epi-Info, versão 7.2.2. Para comparar as distribuições das proporções de cada variável categórica foi aplicado o teste Qui-Quadrado. O nível de significância, $\alpha$, adotado foi de $5 \%$

A pesquisa foi aprovada pelo Comitê de Ética em Pesquisa do Centro de Pesquisa em Medicina Tropical - CEPEM - RONDÔNIA, com Parecer Consubstanciado n.․․ 3.078.766, de 12 de dezembro de 2016, CAAE: 91698818.3.3001.0011.

\section{RESULTADOS}

Na Tabela 1, evidenciou-se predominância do gênero masculino (65,1\%). Ademais, destaca-se a faixa etária de 31 a 49 anos (36,5\%), o estado civil os casados foram a maioria com $(57,1 \%)$ e o quesito religião, o evangélico com percentual de $(61,9 \%)$ como principal religião dos potenciais doadores de órgãos.

Tabela 1 - Distribuição do perfil sociodemográficas dos potenciais doadores de órgãos. Porto Velho Rondônia, 2015-2017.

\begin{tabular}{|c|c|c|c|c|}
\hline Variável & $\mathbf{n}$ & $\%$ & $x^{2}$ & Valor-p \\
\hline \multicolumn{5}{|l|}{ Sexo } \\
\hline Masculino & 41 & $65,1 \%$ & \multirow{2}{*}{5,730} & \multirow{2}{*}{0,0233} \\
\hline Feminino & 22 & $34,9 \%$ & & \\
\hline \multicolumn{5}{|l|}{ Faixa etária } \\
\hline 0 a 17 anos & 8 & $12,7 \%$ & \multirow{4}{*}{10,333} & \multirow{4}{*}{0,0159} \\
\hline 18 a 30 anos & 11 & $17,5 \%$ & & \\
\hline 31 a 49 anos & 23 & $36,5 \%$ & & \\
\hline Acima de 50 anos & 21 & $33,3 \%$ & & \\
\hline \multicolumn{5}{|l|}{ Estado civil } \\
\hline Solteiro (a) & 25 & $39,7 \%$ & \multirow{4}{*}{59,095} & \multirow{4}{*}{$<0,0001$} \\
\hline Casado (a) & 36 & $57,1 \%$ & & \\
\hline Divorciado (a) & 1 & $1,6 \%$ & & \\
\hline Viúvo (a) & 1 & $1,6 \%$ & & \\
\hline \multicolumn{5}{|l|}{ Religião } \\
\hline Agnóstico & 3 & $4,8 \%$ & \multirow{4}{*}{59,603} & \multirow{4}{*}{$<0,0001$} \\
\hline Católico & 20 & $31,7 \%$ & & \\
\hline Espírita & 1 & $1,6 \%$ & & \\
\hline Evangélico & 39 & $61,9 \%$ & & \\
\hline Total & 63 & $100 \%$ & & \\
\hline
\end{tabular}

Fonte: Alcântara FO, Oliveira VC, Fonseca IAC, et al., 2019. 
Os dados foram obtidos a partir da análise de 106 registros de potenciais doadores, $28(26,4 \%)$ tornamse doadores efetivos 15 (14,2\%) foram excluídos por possuírem contraindicações clínica para a doação e 63 $(59,4 \%)$ das famílias que recusaram doar os órgãos de seu familiar falecido durante o período que compreende a pesquisa. Além disso, os resultados possibilitaram realizar perfil dos potenciais doadores de órgão, perfil do responsável por assinar o termo de recusa para não efetivação da doação de órgãos e as causas do óbito, como também a representação dos motivos da recusa familiar quanto a doação".

$\mathrm{Na}$ Tabela 2, constatou-se, como causa morte prevalente dos potenciais doadores, o trauma crânio encefálico $(36,5 \%)$, seguido da morte encefálica $(22,2 \%)$.

Tabela 2 - Distribuição proporcional de Potenciais Doadores de órgãos segundo a causa de óbito. Porto Velho - Rondônia, 2015-2017.

\begin{tabular}{lcccc}
\hline Causa do óbito & $\mathbf{n}$ & $\%$ & $\mathbf{X}^{2}$ & Valor-p \\
\hline Acidente Vascular Cerebral & 9 & $14,3 \%$ & & \\
Acidente Vascular Hemorrágico & 4 & $6,4 \%$ & & \\
Hemorragia subaracnóidea & 13 & $20,6 \%$ & 15,651 & 0,0035 \\
Morte Encefálica & 14 & $22,2 \%$ & & \\
Traumatismo crânio encefálico & 23 & $36,5 \%$ & & \\
\hline Total & $\mathbf{6 3}$ & $\mathbf{1 0 0} \%$ & \\
\hline
\end{tabular}

Fonte: Alcântara FO, Oliveira VC, Fonseca IAC, et al., 2019.

Na tabela 3 mostra o grau de parentesco com o falecido com $(44,4 \%)$ foi cônjuges e $(20,6 \%)$ pai, considerando na linha sucessória parente de primeiro grau. Ademais, destaca-se a faixa etária de 31 a 49 anos. O nível de instrução escolar dos familiares $(41,3 \%)$ deles concluíram o $2^{\circ}$ grau completo e $(17,5 \%)$ eram analfabetos.

Tabela 3 - Distribuição do perfil sociodemográfico do parente responsável por recusa a não efetivação da doação de órgãos. Porto Velho - Rondônia, 2015-2017.

\begin{tabular}{|c|c|c|c|c|}
\hline Variável & $\mathbf{n}$ & $\%$ & $x^{2}$ & Valor-p \\
\hline \multicolumn{5}{|c|}{ Responsável pela doação } \\
\hline Cônjuge & 28 & $44,4 \%$ & \multirow{5}{*}{28,190} & \multirow{5}{*}{$<0,0001$} \\
\hline Irmão (a) & 4 & $6,4 \%$ & & \\
\hline Mãe & 12 & $19,0 \%$ & & \\
\hline Pai & 13 & $20,6 \%$ & & \\
\hline Filho (a) & 6 & $9,6 \%$ & & \\
\hline \multicolumn{5}{|l|}{ Faixa etária } \\
\hline 18 a 30 anos & 9 & $14,3 \%$ & \multirow{3}{*}{10,381} & \multirow{3}{*}{0,0056} \\
\hline 31 a 49 anos & 28 & $44,4 \%$ & & \\
\hline Acima de 50 anos & 26 & $41,3 \%$ & & \\
\hline \multicolumn{5}{|l|}{ Escolaridade } \\
\hline Analfabeto & 11 & $17,5 \%$ & \multirow{6}{*}{31,000} & \multirow{6}{*}{$<0,0001$} \\
\hline 1ํ Grau Incompleto & 7 & $11,1 \%$ & & \\
\hline 1ㅇ Grau Completo & 4 & $6,4 \%$ & & \\
\hline 20 Grau Incompleto & 5 & $7,9 \%$ & & \\
\hline º Grau Completo & 26 & $41,3 \%$ & & \\
\hline Superior & 10 & $15,8 \%$ & & \\
\hline Total & 63 & $100 \%$ & & \\
\hline
\end{tabular}

Fonte: Alcântara FO, Oliveira VC, Fonseca IAC, et al., 2019. 
Figura 2 - Distribuição dos Motivos da Recusa Familiar quanto a doação de órgãos para transplante em Porto Velho - Rondônia, 2015-2017.

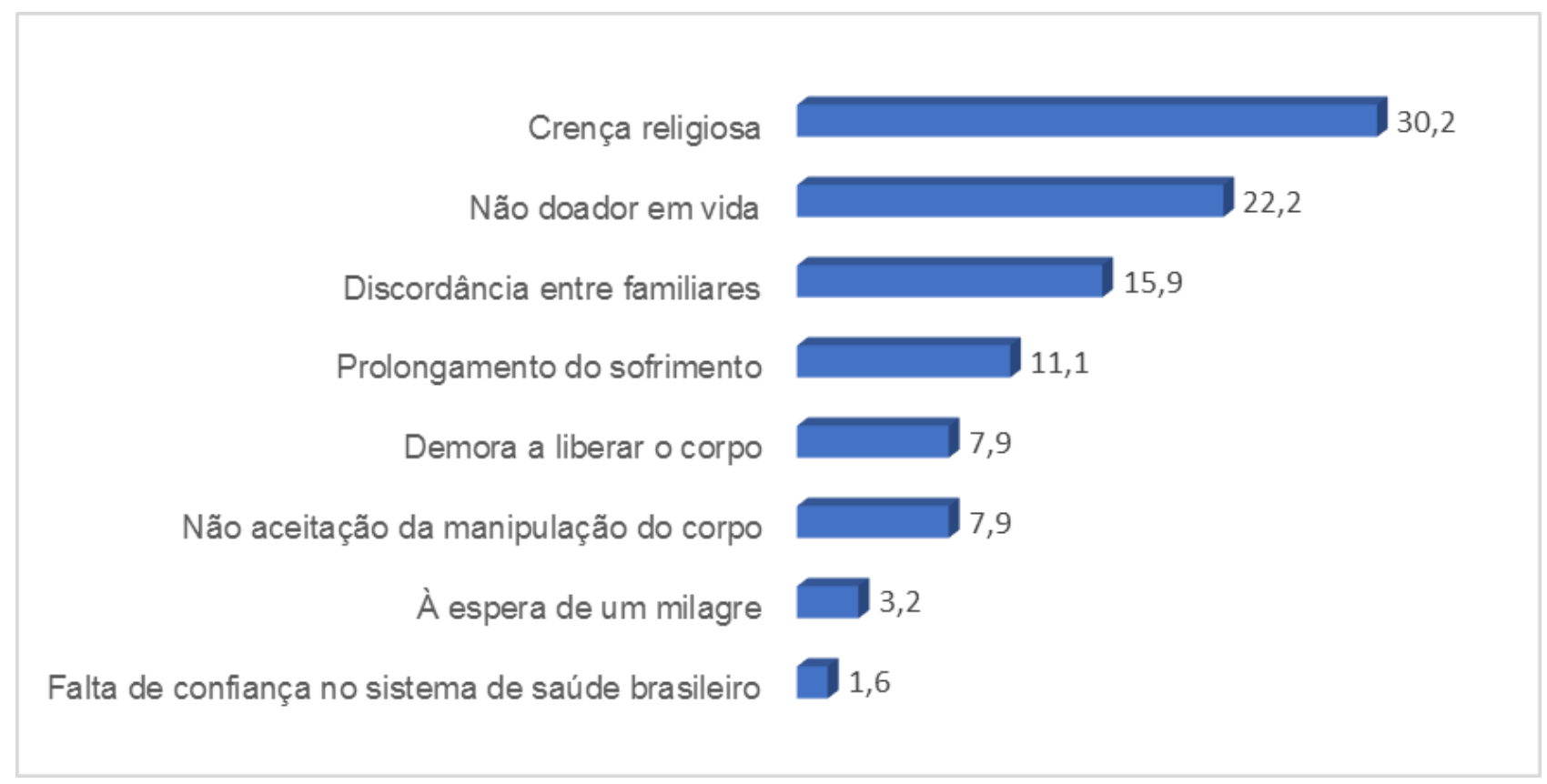

Fonte: Alcântara FO, Oliveira VC, Fonseca IAC, et al., 2019.

\section{DISCUSSÃO}

Por intermédio dessa pesquisa, se demonstra que há predomínio significativo do gênero masculino entre os pacientes em óbito de traumatismo crânio encefálico; $65,1 \%$ do total. Cogita-se outra pesquisa com pacientes em morte de traumatismo crânio encefálico no qual $65,6 \%$ da amostra foram do sexo masculino.

Compara-se essa situação mediante ao sexo masculino estar mais suscetível a inúmeros causas de risco, como atividades laborais, esportes radicais, agressão, bebida, violência, dentre outros. Segundo com a Política Nacional de Atenção Integral a Saúde do Homem, instituída pelo Ministério da Saúde, a vulnerabilidade masculina em ligação aos motivos externos e não externos está relacionada ao comportamento de risco e ao estilo de vida que os mesmos assumem socialmente (BRASIL, 2017).

No que se descreve na faixa etária, salienta-se de 31 a 49 anos com $(36,5 \%)$, seguido dos pacientes com idade entre 18 e 30 anos com (17,5\%). Outras pesquisas no mesmo seguimento confirmam taxas altas nessa faixa etária, mostrando um percentual de $53,8 \%$ até os 45 anos de idade e $46,2 \%$ acima dos 45 anos de idade.

No estudo relativo à causa do óbito, a principal causa foi traumatismo crânio encefálico (36,5\%) do total, em seguida a morte encefálica, $(22,2 \%)$. As informações expostas vão de encontro aos de outra pesquisa realizado no Estado do Ceará, no qual o trauma craniano aparece com 51,4\%, e o evento cerebral com $31,4 \%$.

Fernandes FS (2015), evidenciou-se a predominância do TCE Grave, as causas do coma são diversas, podendo ocorrer naturalmente como consequência de um TCE, no contexto de acidentes automobilísticos ou agressões; hemorragia subaracnóidea, ligada à ruptura de aneurisma; lesão difusa do cérebro após a Parada Cardiorrespiratória (PCR) revertida; hemorragia cerebral espontânea maciças.

A legislação brasileira preconiza que a autorização familiar para retirada de órgãos e tecidos em doador falecido, seja efetivada entre parentes maiores de idade, obedecida a linha sucessória, reta ou colateral, até segundo grau inclusive, firmada em documento subscrito por duas testemunhas presentes à verificação da morte (BRASIL, 2017). 
Na cidade do Piauí, de 21 familiares que recusaram a doação, o grau de parentesco foi de $38,1 \%$ cônjuge e $23,8 \%$ pai. Em Sergipe, na entrevista familiar, os cônjuges (35,3\%) foram os principais envolvidos na recusa da doação (BARRETO MB et al., 2016).

Foi possível detectar que o principal motivo da recusa familiar se refere à a crença religiosa é referida como a principal causa da recusa, vale salientar que até o presente no Brasil nenhuma religião mostrou uma postura desvantajosa em relação à doação de órgão. Observa-se que neste estudo é que os envolvidos realizam interpretações pessoais sobre os livros doutrinários. No Brasil há uma enorme prevalência da religião católica seguida dos evangélicos (IBGE, 2010).

Outra causa da recusa a doação foi que ente falecido não era doador em vida. A maioria das pessoas não toma a decisão de ser um doador em vida e mesmo aqueles que o fazem não compartilham tal decisão com a família, o que acaba se tornando um empecilho à doação de órgãos (RECH TH e RODRIGUES FILHO EMR, 2014).

Goldim DFS (2014) salienta que a maioria das pessoas não comunicam a família a sua decisão de ser um doador. Quando a família conhece o desejo de seu familiar em relação ao destino de seus órgãos a tomada de decisão se torna mais fácil, ao passo que o seu desconhecimento dificulta a tomada de decisão e está associado a maiores taxas de negativa.

Discórdia entre familiares na tomada de decisão perfazendo $(15,9 \%)$ dos casos de recusa familiar, na pesquisa de Santos MCKB (2014), sobre a objeção dos familiares, foi exposto através dos resultados que alguns parentes concordavam com a doação de órgãos, mas outros, da mesma parentela, não consentiam e isso motivou na recusação, pois os mesmos escolheram por obedecer o parecer do outro familiar que se negou a doar os órgãos do falecido.

Ao serem abordados sobre o momento da solicitação da doação de órgãos de seu ente recém-falecido, os familiares revelaram sentimentos, dúvidas e opiniões que puderam ser sistematizados nos seguintes núcleos de sentido (GARCIA AJ, 2015). A família tende a reagir e a expressar seus sentimentos frente à perda exatamente nesse momento. Em meio ao desespero e confusão emocional, ela precisa tomar uma decisão importante sobre o desfecho dessa história (PEREIRA JLE, 2017). Foi observado também nesta pesquisa que parte das recusas se referem ao prolongamento no sofrimento dos familiares se refere ao prolongamento no sofrimento dos familiares demora no processo de retirada dos órgãos e liberação do corpo é um fator relevante nos casos de recusa. A família, que vive um momento de grande estresse emocional, ao ser informada sobre a necessidade de o corpo de seu ente querido permanecer por mais tempo no hospital, para que as equipes de transplante possam retirar os órgãos, tenderá a ser desfavorável à doação (FROTA AR, 2015).

Dentre os motivos da recusa familiar está a demora em libera o corpo no processo de doação. Os sentimentos afloram e os familiares que aguardam a liberação do corpo para a preparação do velório que caracteriza como um momento de angústia, sofrimento e nervosismo mediante 0 ato da espera (ALCÂNTARA DF, 2013).

Um dos motivos da recusa familiar se refere à não aceitação da manipulação do corpo, acredita-se que o corpo ficara deformado e não terá como velá-lo com o caixão aberto ou faltara partes do corpo que ficarão visíveis. Os parentes presumem que o corpo se trata de algo inviolável, considerando essencial o culto ao corpo presente, e dessa maneira deve continuar intocável. Segundo Roza BA et al. (2015), ao manusear esse corpo para remoção dos órgãos, os familiares entendem como falta de respeito ao falecido, acabam desistindo da doação.

No estudo de Peixoto DS (2014), o familiar tem dificuldade em aceitar a manipulação do corpo do parente com a finalidade de retirada de órgãos para transplante, e a não aceitação é motivo para negar a doação, por acreditar que o corpo é o templo sagrado de Deus e é intocável.

O luto, quase sempre, abrange questões religiosas, transformando-se como um alicerce de apoio para amenizar a perda, da mesma maneira, muitos familiares utilizam a religião como fuga ou desculpa para 
alegar o impedimento da recusa da doação, pois os mesmos afirmam que esperam por um milagre ou que a permissão da doação é o mesmo que concordar ou sentenciar o óbito do ente querido (GARCIA AJ, 2015).

Falta de confiança no sistema de saúde também se apresentou como uma causa influenciadora na tomada de decisão. A assistência hospitalar só reflete a decepção dos familiares com a omissão das informações e concentração dadas pelos profissionais da saúde e a maneira como foram abordados durante as ocorrências do dia-a-dia no atendimento (MORAES EL, 2016). Várias campanhas mostram a necessidade dos indivíduos dialogar sobre o tema doação no ambiente familiar, os familiares conhecendo a vontade do ente falecido torna-se mais fácil a decisão, sendo respeitada na maioria das vezes (FROTA AR, 2015).

\section{CONCLUSÃO}

A principal causa mais mencionada para a recusa familiar, foi a crença religiosa, desejo do doador em vida, discórdia entre familiares, prolongamento no sofrimento, demora a liberar o corpo, a não aceitação da manipulação do corpo, a espera de um milagre e a falta de confiança no sistema de saúde brasileira. Sugere-se por intermédio dessa pesquisa proporcionar o desenvolvimento de outros estudos no mesmo assunto, como nortear políticas que se empreguem na dispersão de dados a respeito da doação de órgãos, propiciando discussões na população. Assim, a população toma entendimento da necessidade dos vários indivíduos que esperam por um ato de solidariedade e humanidade nas filas de transplantes.

\section{REFERÊNCIAS}

1. ABTO. 2017. Associação Brasileira de Transplante de órgãos. São Paulo: sobre transplante/perguntas e respostas sobre doação de órgãos e transplante.

2. ALCÂNTARA DF. Opinião e conhecimento da população da cidade de Curitiba sobre doação e transplante de órgãos. Rev Assoc Méd Brás. 2013.

3. BARRETO MB et al. Fatores relacionados à não doação de órgãos de potenciais doadores no estado de Sergipe, Brasil. Rev Bras Pesq Saúde. 2016.

4. BRASIL. Portaria GM n. 905, de 16 de agosto de 2000. Cria a Comissão Intra-Hospitalar de Transplantes. In: BRASIL, Ministério da Saúde. Legislação sobre transplantes no Brasil, Brasília, 2017.

5. DALBEM GG; CAREGNATO RCA. Doação de órgãos e tecidos para transplante: recusa das Famílias. Texto Contexto Enferm, Florianópolis, 2014 Out-Dez; 19(4): 728-35.

6. FERNANDES, F, S. Sofrimento e contradição: o significado da morte e do morrer para enfermeiros que trabalham no processo de doação de órgãos para transplante. São Paulo. Enferm Glob. 2015.

7. FROTA AR. Fatores que influenciam a recusa familiar no processo de doação de órgãos e tecidos para transplantes. J Bras Transpl, São Paulo, 2015.

8. GARCIA AJ. Stress e captação de órgãos: uma realidade vivenciada pelos enfermeiros [dissertação]. São Paulo: Universidade de São Paulo, Escola de Enfermagem; 2015.

9. GOLDIM DFS. Transplante de órgãos: bases fisiopatológicas e técnicas. São Paulo: Atheneu, 2014, p. $158-169$.

10. KUNG MLJ. Transplantes de órgãos e tecidos. Revista Acta Médica. v.1, n.2, São Paulo, 2015.

11. LIRA GG et al. Ponderações de familiares sobre a decisão de recusar a doação de órgãos. Acta Paul Enferm. 2012.

12. MORAES EL. Trauma e doação de órgãos e tecidos para transplante. JBT J Bras Transpl. 2016.

13. NEVES JOM. Entenda a doação de órgãos: decida-se pela vida. Informativo da Associação Brasileira de Transplante de Órgãos. São Paulo. 2015.

14. NUNES et al. Experiência no projeto doe vida: influência na concepção da Doação de órgãos através de novas abordagens de ensino. Rev. Extendere, v.2 n.1, jul.dez.2013.

15. PEREIRA JLE. Avaliação das causas de recusa familiar a doação de órgãos e tecidos. Acta paul. Enferm., São Paulo, v. 26, n. 4, 2017.

16. PEIXOTO DS. Morte Encefálica, Cuidados ao Doador de Órgãos e Transplante de Pulmão. Rev Bras Ter Intensiva, São Paulo, 2014.

17. RECH TH, RODRIGUES FÉMR. Entrevista familiar e consentimento. Revista Brasileira de Terapia Intensiva. São Paulo, vol. 19, n. 1, jan./mar., 2014. p. 87.

18. ROZA BA, et al. Doação de órgãos e tecidos: relação com o corpo em nossa Sociedade. Acta Paul Enferm. São Paulo, 2015.

19. SANTOS MJ, MASSAROLLO MCKB. Processo de doação de órgãos: percepção de familiares cadáveres. Rev Latino-am Enferm. São Paulo. 2015.

20. SANTOS MCKB. Recusa de doação de órgãos e tecidos para transplante relatados por familiares de potenciais doadores. Acta Paul Enferm. São Paulo. 2014.

21. WAKEFIELD CE et al. Influências religiosas e étnicas na disposição de doar órgãos e comportamento de doadores: uma perspectiva australiana. Prog Transplant. 2011; 21 (2): 161-8. 